\title{
Long-Term Modifiability of Anomalous and Delayed Rectification in Guinea Pig Inferior Olivary Neurons
}

\author{
Y. Yarom ${ }^{1}$ and R. Llinás \\ 'Department of Neurobiology, Institute of Life Sciences, Hebrew University of Jerusalem, Jerusalem, Israel, \\ and Department of Physiology and Biophysics, New York University Medical Center, New York, \\ New York 10016
}

Delayed and anomalous rectification was studied in inferior olivary (I.O.) neurons in guinea pig brain stem slices maintained in vitro. Hyperpolarization of the I.O. cell beyond rest membrane potential was accompanied by anomalous rectification (AR). This consisted of 2 parts: an instantaneous and a time-dependent component. The "instantaneous" component was blocked by bath addition of $\mathrm{Ba}^{2+}$ or $\mathrm{Cs}^{+}$and demonstrated inactivation following prolonged hyperpolarization. The time-dependent component, referred to as the $\mathrm{g}_{\mathrm{k}(0))}$, was blocked by harmaline in concentrations of $0.1 \mathrm{mg} /$ $\mathrm{ml}$ or by substitution of $\mathrm{Co}^{2+}, \mathrm{Cd}^{2+}$, or $\mathrm{Mn}^{2+}$ for $\mathrm{Ca}^{2+}$ in the bath. The $\mathrm{g}_{\mathrm{k}(\mathrm{ol})}$ was blocked by extracellular $\mathrm{Cs}^{+}$but not by $\mathrm{Ba}^{2+}$. Delayed rectification (DR), consisting of 2 distinct components, was observed after membrane depolarization by more than $10 \mathrm{mV}$ with respect to rest (usually at -65 $\mathrm{mV}$ ). One of the components of the DR was found to be quite similar to the classical $g_{k}$. It did not demonstrate significant inactivation with membrane potential change and was reduced by $\mathrm{Ba}^{2+}$ or tetraethylammonium (TEA). A second component of the DR demonstrated voltage-dependent inactivation and was thus referred to as $\mathbf{g}_{\mathrm{k}(\text { inact) }}$. This inactivation determined by current-clamp measurements had a sigmoidal time course, with approximately a 1 sec onset latency and a half-time to peak of $7 \mathrm{sec}$. The inactivation of $\mathbf{g}_{\mathrm{k}(\text { inact) }}$ outlasted current injection for tens of seconds to several minutes, depending on the duration and amplitude of the preceding depolarization. During this period, I.O. neurons could be easily activated and demonstrated full dendritic spikes following current injection or excitatory synaptic input that had previously been subthreshold for spike initiation. The inactivation component of the DR was removed by prolonged membrane hyperpolarization beyond rest. $g_{k \text { (inact) }}$ was blocked by 4-aminopyridine (4-AP; $100 \mu \mathrm{M}$ ) but not by $\mathrm{Ba}^{2+}$. This inactivation was dependent on the presence of extracellular $\mathrm{Ca}^{2+}$ or $\mathrm{Ba}^{2+}$. Addition of $\mathrm{Co}^{2+}$ or $\mathrm{Cd}^{2+}$ to the bath did not block $g_{\text {k(inact) }}$ but did prevent its inactivation.

The modulatory effects of these different membrane conductances on the integrative properties of I.O. neurons are described. The long duration of the inactivation of DR and

\footnotetext{
Received Jan. 24, 1986; revised Sept. 2, 1986; accepted Oct. 17, 1986.

Research was supported by United States Public Health Service Grant NS13742 from the National Institute of Neurological and Communicative Disorders and Stroke.

Correspondence should be addressed to Dr. R. Llinás, Department of Physiology and Biophysics, New York University Medical Center, 550 First Avenue, New York, NY 10016.

Copyright (c) 1987 Society for Neuroscience $0270-6474 / 87 / 041166-12 \$ 02.00 / 0$
}

AR is considered as the basis for a dynamic long-term modulation of the electroresponsive and integrated properties of I.O. neurons.

In previous publications, we indicated that mammalian inferior olivary (I.O.) cells are capable of rather complex electrophysiological behavior (Llinás and Yarom, 1981a, b). Thus, $\mathrm{Ca}^{2+}$ dependent action potentials may be generated at both the dendritic and the somatic levels in these neurons. At the former, they are generated by a noninactivating $\mathrm{Ca}^{2+}$ conductance, while at the latter, they are produced by a $\mathrm{Ca}^{2+}$ conductance that is inactive at resting potential but may be deinactivated by membrane hyperpolarization. In addition to these 2 conductances, a voltage-dependent $\mathrm{Na}^{+}$conductance is displayed by I.O. neurons that generate fast somatic action potentials and both voltage- and $\mathrm{Ca}^{2+}$-dependent $\mathrm{K}^{+}$conductances. In this paper we will discuss 4 other conductances; 2 of these are responsible for delayed rectification (DR); 1 of these resembles the classical delay rectifier $g_{K}$ (Hodgkin and Huxley, 1952), while the second inactivates with voltage $g_{K(\text { inact) }}$. The other 2 conductances generate anomalous rectification (AR). The $\mathrm{g}_{\mathrm{K}(\text { inact) }}$ resembles in some, but not all, respects the so-called A current in Hermissenda (Alkon, 1984) and, to a lesser extent, the $M$ currents in sympathetic neurons (Adams et al., 1982) and in hippocampal pyramidal cells (Halliwell and Adams, 1982). Of the 2 anomalous rectifiers, 1 is observed as an "instantaneous" conductance change during membrane hyperpolarization and is similar to that initially described in striated muscle (Katz, 1949; Adrian, 1969) and subsequently in the olfactory bulb (Scholfield, 1978; Constanti and Galvan, 1983) and other neurons (Thompson and Aldrich, 1980). The second is a time-dependent conductance that in some respects is similar to the so-called $Q$ current observed in hippocampal pyramidal cells (Halliwell and Adams, 1982), but that in other respects is clearly different from that current. Because of its difference from the $Q$ current, we will refer to this latter conductance as the $\mathrm{g}_{\mathrm{K}(\mathrm{ol})}$, denoting its inferior olivary origin.

This paper studies slow voltage-dependent conductance changes that modulate the integrative properties of the inferior olive. These conductances are activated by both de- and hyperpolarizing membrane potential changes and are modulated by bioactive substances, such as serotonin and harmaline. Because both positive and negative variations of the membrane potential have been shown to have a significant effect on I.O. neuron excitability (Llinás and Yarom, 1981), we consider the phenomena described here significant in the overall function of these neurons in vivo. Indeed, the modulations occurring after 


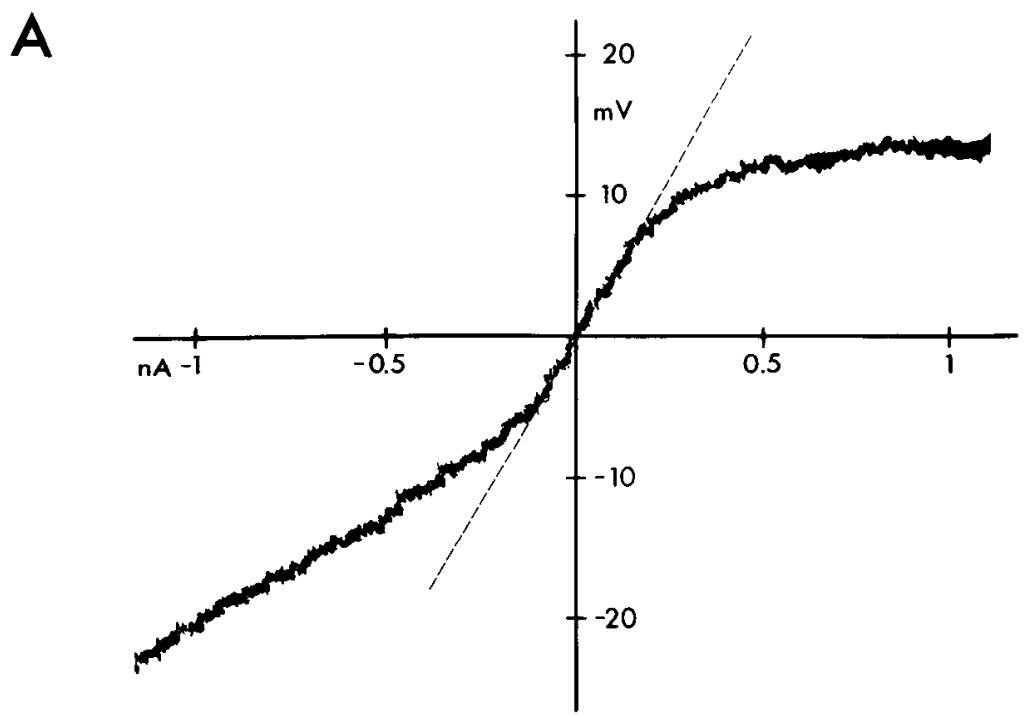

Figure 1. Current-voltage relation in

B

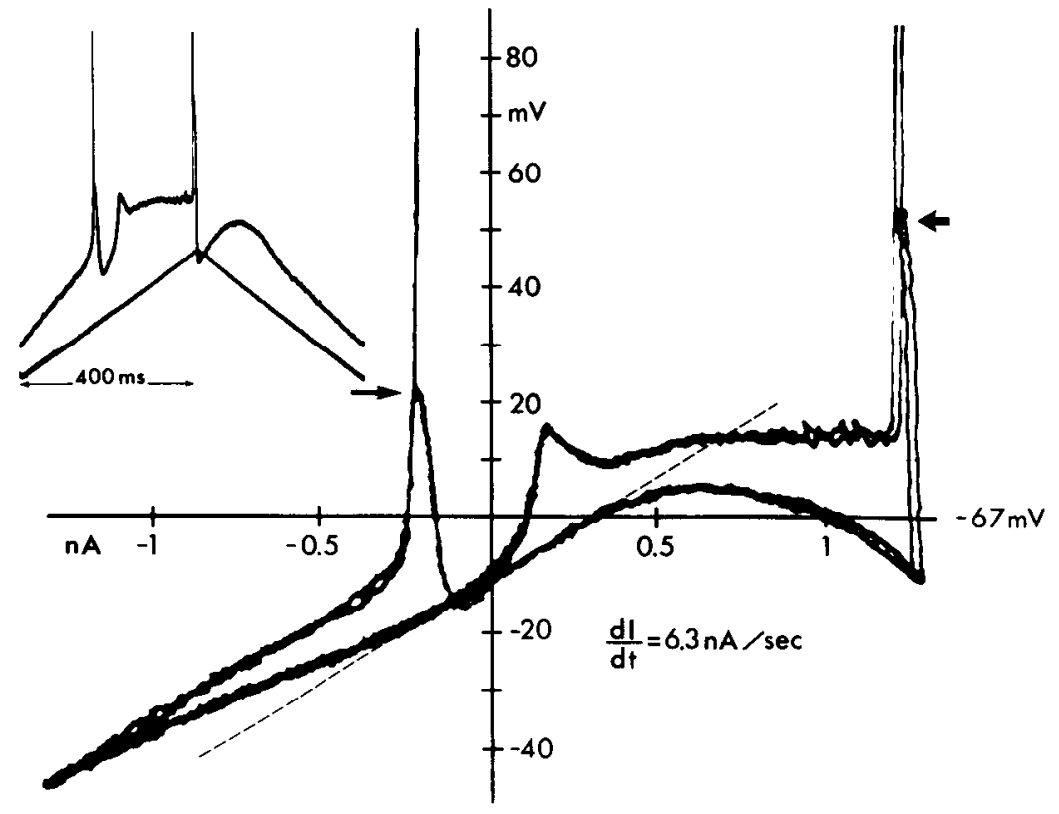

I.O. neuron. $A$, Potential is generated by a ramp current from an initial level of $-1.3 \mathrm{nA}$, linearly rising in $1 \mathrm{sec}$ to $+1.3 \mathrm{nA}$. The trajectory of the potential indicates the presence of AR (lower left quadrant) and of delayed rectification (upper right), and of a region of linear membrane properties around 0 current. The resting potential was $-65 \mathrm{mV}$; the broken line indicates the slope of linear resistance. $B$, Membrane potential obtained by a double-ramp current injection having a rise time of $400 \mathrm{msec}$ and a total amplitude of $2.6 \mathrm{nA}$ peak-topeak. Resting potential prior to this repeated ramp stimulus was $-67 \mathrm{mV}$. The trace is composed of 2 successive double-ramp injections to illustrate the reproducibility of the response. The voltage trace indicates the presence of 2 firing levels, 1 at $-10 \mathrm{mV}$ negative to rest and the second at $+15 \mathrm{mV}$ from rest value, corresponding, respectively, to the low-threshold spike and the somatic $\mathrm{Na}^{+}$spike. Rate of rising of the current, $6.3 \mathrm{n} \Lambda /$ sec. membrane potential changes within normal physiological ranges bestow upon I.O. cells in vitro a protracted form of hysteresis that produces long-term modulations of both their integrative and oscillatory properties.

\section{Materials and Methods}

The materials and methods used in these experiments were the same as those described in previous publications on in vitro inferior olive (Llinás and Yarom, 1981a, b). The results were obtained from guinea pig brain stem slices maintained at $37^{\circ} \mathrm{C}$ under oxygenated Ringer's solution. In experiments with ion substitutions, such as the addition of $\mathrm{Cd}^{2+}$ or $\mathrm{Ba}^{2+}$, the Ringer's composition was similar to that in previous experiments (Llinás and Sugimori, 1980). Harmaline $(200 \mu \mathrm{g} / \mathrm{ml})$ and 4-aminopyridine (4-AP; $100 \mu \mathrm{M}$ ) final concentrations were added to the bathing solution. TTX was added to the bath to a final concentration of $10^{-5} \mathrm{gm} / \mathrm{ml}$, and tetraethylammonium (TEA) at a final concentration of $10 \mathrm{~mm}$. The methods for brain slicing and the electronic instrumentation have also been described previously (Llinás and Sugimori, 1980)

The data base of the present study was comprised of the results of successful intracellular studies of more than 200 neurons. In general, as in our previous work, cells could be held for up to $4 \mathrm{~h}$ without showing any signs of deterioration. In the double-current ramp experiments, currents were injected through the bootstrap bridge of the amplifier (Neurodata model IR282) from a Wavetek (model 164). The data were taped and later displayed on a storage oscilloscope (Tektronix 611) and printed directly, using a hardcopy unit. In double-ramp experiments, the results were displayed as Lissajous figures by activating the horizontal axis of the cathode ray tube with the ramp current itself, while the voltage was displayed on the vertical axis (see Fig. 1).

\section{Results}

Nonlinear membrane properties in the inferior olive as tested by double-ramp current injection

The voltage-current relationship observed in I.O. neurons following current injection through the recording microelectrode is demonstrated in Figure $1 \boldsymbol{A}$ for a ramp depolarization with a rate of rise of $2.6 \mathrm{nA} / \mathrm{sec}$. At this rate of current injection, action potentials were not generated and the membrane resistance 


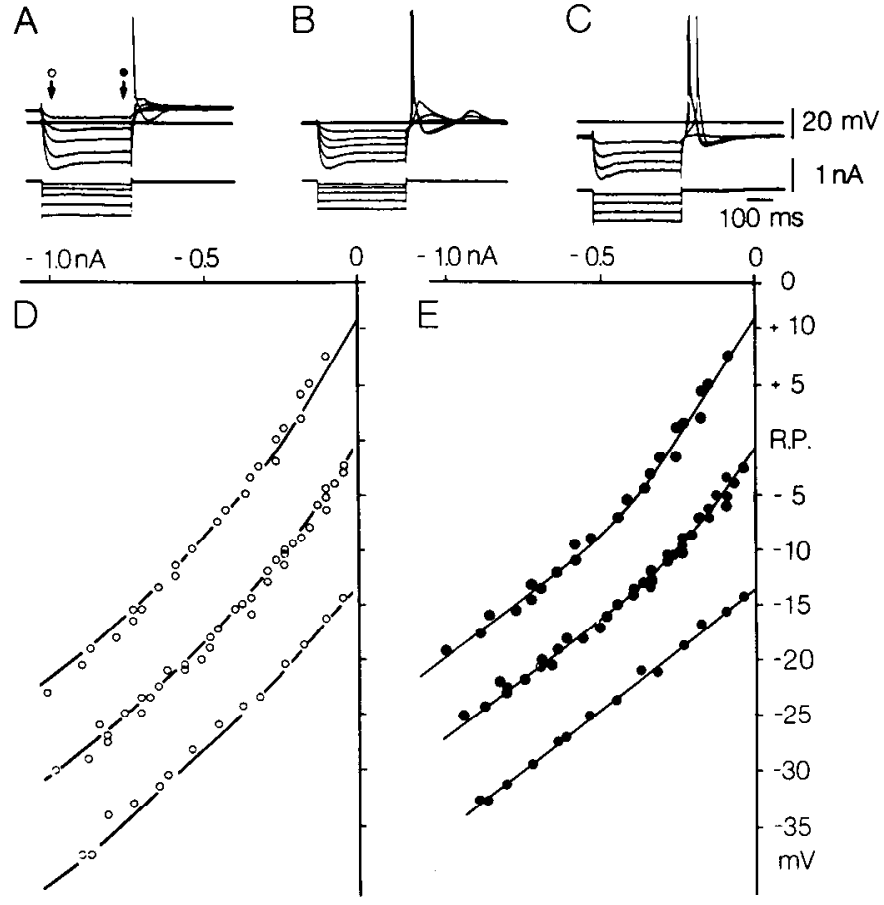

Figure 2. Anomalous rectification observed by hyperpolarizing current steps at different rest membranc values. $A, B, C$, Similar records obtained at $+11 \mathrm{mV}(A)$ and $-14 \mathrm{mV}(C)$ with respect to rest $(B)$. The plot in $D$ shows the amplitude of the peak hyperpolarization at 3 levels of membrane potential, illustrated in $A-C$ as a function of current. The upward curvatures of these plots indicate an increased membrane conductance with hyperpolarization. $E$, Amplitude of the plateau potential at the 3 membrane levels is plotted. This time-dependent conductance increase reaches a maximum conductive state at approximately $-8 \mathrm{mV}$ from rest, as observed by the break in the I-V plot, for the records obtained at $+11 \mathrm{mV}$ and at resting potential (R.P.). At $-14 \mathrm{mV}$, the amplitude of this plateau is linearly related to the injected current. Solid lines in the upper $2 I-V$ plots in $E$ indicate the conductive state prior to the activation of the time-dependent AR; the broken lines, the input resistance following the onset of this conductive state.

reached was close to steady state at each current level (an exception was the slow inactivation of DR and AR, which occurred over several seconds and thus was not visible at this rate of membrane polarization). This current-voltage relation may be described as being composed of 3 parts (Fig. 1A): a linear component that passed through 0 current and had an approximate slope resistance of $46 \mathrm{M} \Omega$ (indicated in Fig. $1 A$ by the broken line); a deviation from this slope when the membrane was depolarized beyond $8 \mathrm{mV}$ from rest; and another deviation when the membrane was hyperpolarized beyond approximately $6 \mathrm{mV}$ from rest.

A more dynamic presentation of the current-voltage relationship was obtained by the transmembrane injection of a biphasic current ramp with a rise time of $400 \mathrm{msec}$ (Fig. $1 B$ ). This record, taken from the same I.O. cell as that in Figure $1 A$, is displayed conventionally as voltage and current against time in the inset in Figure $1 B$. Under these conditions, the cell fired at 2 different levels (Llinás and Yarom, 1981a). As the trajectory of the membrane potential was followed from the most hyperpolarized point at $-1.3 \mathrm{nA}$ towards the depolarizing level, the first action potential was seen to occur at $-77 \mathrm{mV}$, i.e., $10 \mathrm{mV}$ negative to the resting membrane potential. This somatic $\mathrm{Ca}^{2+}$ dependent spike, the "low-threshold spike," was usually observed as a rebound from the afterhyperpolarization (AHP) that follows normal I.O. action potentials (Llinás and Yarom, 1981a). In Figure $1 B$, the "rebound" spike is observed as the membrane is steadily depolarized from a negative potential level $(-110$ $\mathrm{mV}$ ). In this case the low-threshold spike was large enough to trigger a $\mathrm{Na}$-dependent fast action potential (arrow) and was followed by an AHP that brought the membrane close to -82 $\mathrm{mV}$. As the membrane continued to be depolarized, a second rebound response was observed. This second response did not reach the firing level for $\mathrm{Na}^{+}$spike activation and was followed by a small $\Lambda \mathrm{HP}$.

Aside from this new value (approximately $10 \mathrm{mV}$ positive with respect to rest), the membrane potential showed very little change in amplitude despite the linearly rising outward current injection. This flattening of the current-voltage relation produced an almost steady-state voltage plateau, which was abruptly terminated by the activation of a $\mathrm{Na}$-dependent spike, followed by a $\mathrm{Ca}^{2+}$-dependent after depolarization (Fig. $1 B$, arrow right). This was the "high-threshold spike" (Llinás and Yarom, 1981a). As the current was changed to an inward ramp, the membrane potential (which at that time was negative with respect to the resting level because of the AHP that followed the dendritic $\mathrm{Ca}^{2+}$ spike) returned and overshot the resting level, following a convex trajectory, and crossed the resting level again at about $0.03 \mathrm{nA}$ inward current. This and the fact that at 0 current the membrane potential is $-11 \mathrm{mV}$ indicated that 200 msec after the dendritic $\mathrm{Ca}^{2+}$ spike, the Ca-dependent $\mathrm{K}$ conductance $\mathrm{g}_{\mathrm{K}(\mathrm{Ca})}$ was still activated (Llinás and Yarom, 1981a). The upward deviation of the potential from an arbitrary linear trajectory (Fig. $1 B$, broken line) observed below $-67 \mathrm{mV}$ denoted the marked AR, also illustrated in Figure $1 A$. As the ramp current returned to the depolarizing direction, the voltage record showed a certain hysteresis, indicating an increased conductance as the potential was moved in the depolarizing direction. At this point, the cycle began once again. The 2 successive cycles superimposed in Figure $1 B$ overlap quite closely, illustrating the repeatability of these voltage trajectories.

The conductances that underlie the DR and AR dominate the basic nonlinear steady-state properties of I.O. neurons. Their ionic selectivity and pharmacological properties, as well as voltage and time modifiability, are the main focus of this study.

\section{Anomalous rectification}

General description

The basic properties of the anomalous rectification seen in I.O. cells are shown in Figure 2. Here, hyperpolarizing pulses were given at different membrane potentials. In Figure $2 A$ the membrane has been depolarized from -67 to $-56 \mathrm{mV}$. From this new level, hyperpolarizing current pulses (approximately 300 msec) generated a potential change characterized by a rapid hyperpolarizing phase followed by a slow partial repolarization that reached a plateau level. At the end of the current pulse, the return to baseline was followed by a rebound low-threshold spike on which $\mathrm{Na}^{+}$-dependent action potentials were generated. Similar sets of experimental results were obtained from the resting level $(-67 \mathrm{mV}$; Fig. $2 B)$ and after $14 \mathrm{mV}$ hyperpolarization $(-81 \mathrm{mV}$; Fig. $2 C$ ). These records are plotted in Figure 2, $D, E$, where open circles represent voltage values measured at the peak of the hyperpolarizing voltage and the closed circles at the steady-state plateau. (This convention is followed in the remaining figures.) The progressively decreasing slope in Figure $2 D$ indicates an increased conductance that is characteristic of AR. This increase, which produces the devia- 


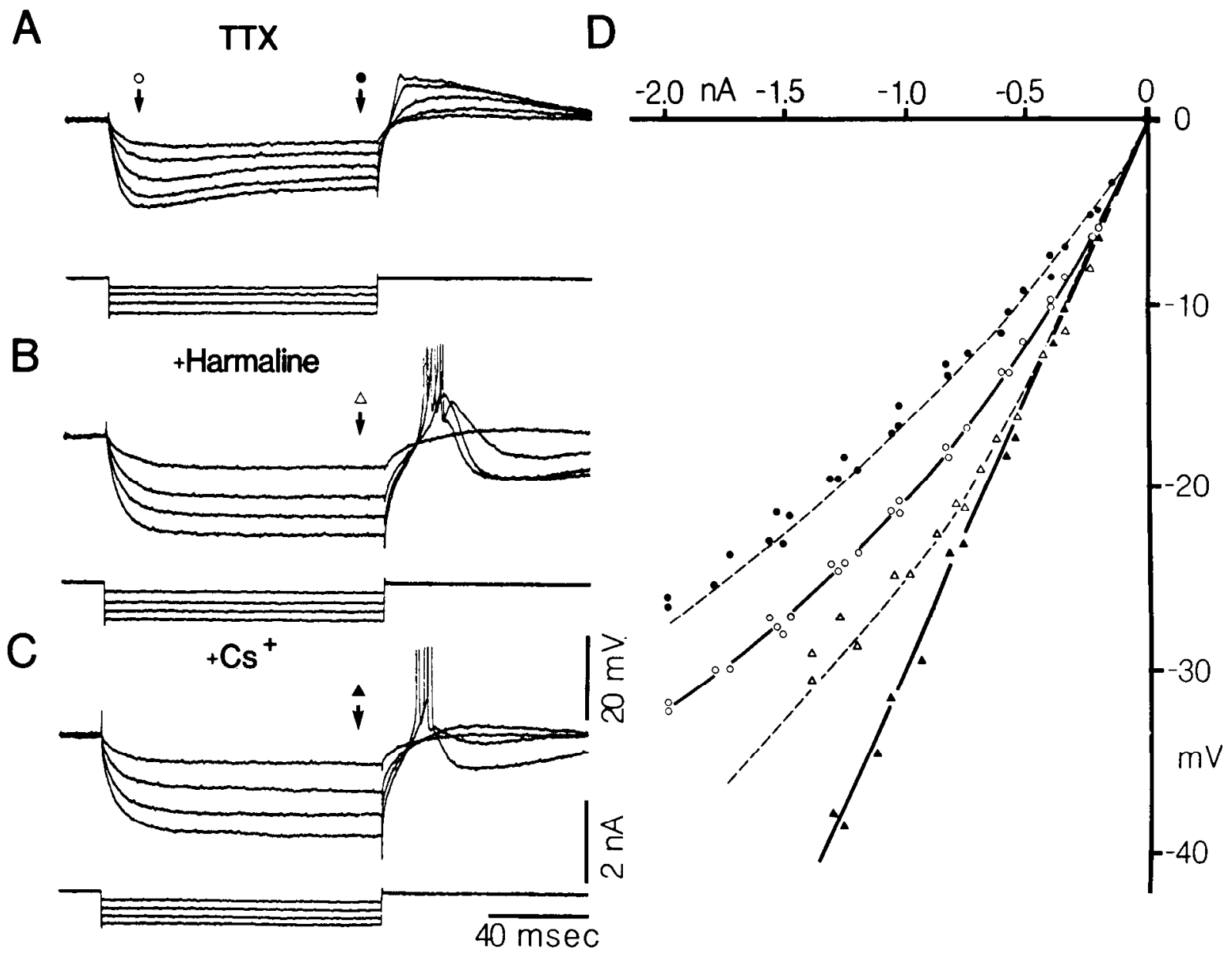

Figure 3. Effects of harmaline and $\mathrm{Cs}^{+}$on AR. A, Control responses in the presence of TTX to hyperpolarizing pulses delivered from rest. The peak and the plateau deflections are plotted to the right in $D$ as closed and open circles, respectively. $B$, Harmaline $(15 \mu \mathrm{g} / \mathrm{ml}) \mathrm{produced}$ a blockage of the time-dependent AR and an increase of the rebound action potentials (spikes are truncated). Plot of the maximum amplitude of the voltage is shown as open triangles in $D$, indicating that although the time-dependent conductance is blocked, an instantaneous component remains, producing an upward deviation of the plot. $C$, Addition of $\mathrm{Cs}^{+}$eliminates the instantaneous component of the AR, as observed in $D$ (closed triangles) from the linear relation and increased amplitude of the response.

tion from linearity of the current-voltage plots (Fig. $2 D$ ), is activated quite rapidly. We refer to this component as an "instantaneous AR" to indicate that it is activated more quickly than the membrane time constant. (That this reduction in peak voltage is not due to different onset times for the time-dependent component of this $\mathrm{AR}$, or to changes in the time constant of the cell, can be demonstrated by the removal of the time-dependent component of this conductance by harmaline, as described below.) The plot of the plateau potential (Fig. 2E) indicates that the membrane has a second time-dependent conductance state. The fact that the shape of this plot becomes linear at voltages negative to $-15 \mathrm{mV}$ from resting levels indicates that the AR has reached a maximum activation state. Since the properties of this time-dependent AR are unique to the I.O. neurons, we refer to this $A R$ as $\mathrm{g}_{\mathrm{K}(0) 1}$.

\section{Effects of harmaline and $\mathrm{Cs}^{+}$}

The above description suggests that AR in the inferior olive may be comprised of 2 distinct components, 1 "instantaneous" and 1 time-dependent. This suggestion is supported by the observation that harmaline blocks the time-dependent component of the AR, while the instantaneous conductance is unaffected.
Harmaline, an active alkaloid of harmala, has a specific action on I.O. neurons in vivo (de Montigny and Lamarre, 1973; Llinás and Volkind, 1973). In in vitro preparations, harmaline, at concentrations of $0.1 \mathrm{mg} / \mathrm{ml}$, has been observed to both hyperpolarize the neuron and increase the somatic $\mathrm{Ca}^{2+}$ excitability by shifting the inactivation curve to less negative values (Llinás and Yarom, 1986). We now demonstrate that, in addition, harmaline specifically blocks the time-dependent component of AR. The effect of harmalinc on AR is shown in Figure 3. The input resistance of this I.O. neuron was determined initially at resting level $(-65 \mathrm{mV})$. The deviation from this initial potential after the addition of harmaline was corrected by DC injection through the recording electrode. The control record in Figure $3 A$ shows both aspects of the rectification. Values for the peak and the plateau voltage response are plotted in Figure $3 D$. Addition of $0.1 \mathrm{mg} / \mathrm{ml}$ of harmaline to the bathing solution (Fig. $3 B$ ) blocked the time-dependent component of the rectification, as indicated by the lack of repolarization following the initial onset of the voltage transient (compare Fig. $3 A$ with $B$ ). Note, however, that the instantaneous AR is unchanged, as determined by the upward deviation of the current-voltage plot (open triangles, Fig. $3 D$ ). Moreover, there was an increase of the re- 


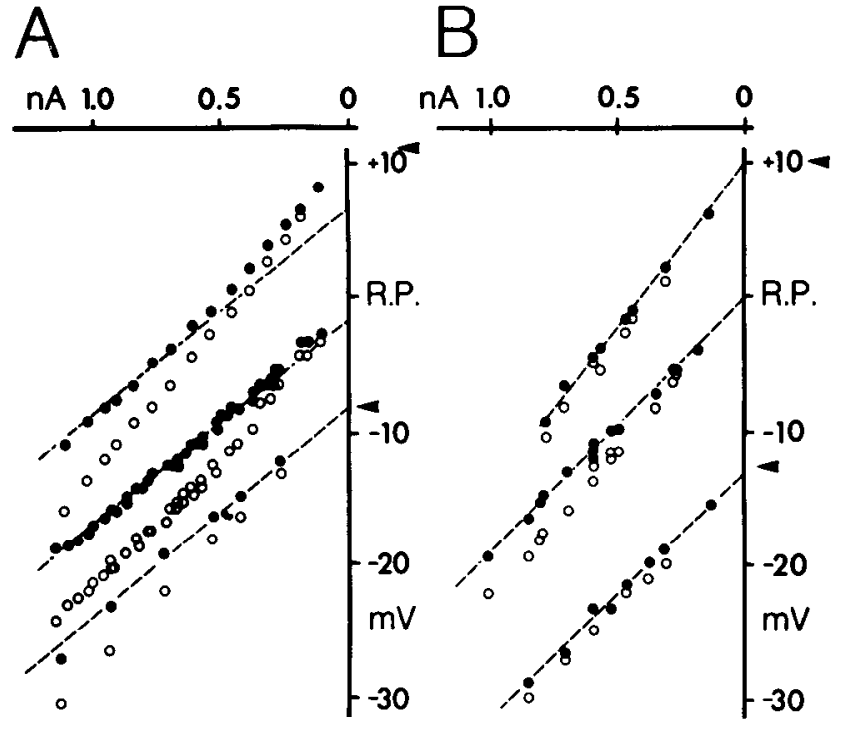

Figure 4. Effects of $\mathrm{Mn}^{2+}$ and lack of extracellular $\mathrm{Ca}^{2+}$ on $\mathrm{g}_{\mathrm{K}(\mathrm{ol}) \cdot}$. A, Plot shows the amplitude of the peak (open circles) and plateau (closed circles) hyperpolarization as a function of the current pulse under normal conditions at 3 different levels of membrane potential. $B$, Same as in $A$ after $\mathrm{Mn}^{2+}$ has been substituted for $\mathrm{Ca}^{2+}$, demonstrating the reduction in the time-dependent AR. The records in $A$ were obtained in the same cell as those in $B$ after $\mathrm{Ca}^{2+}$ had been reintroduced following the results illustrated in $A$.

bound spike amplitude and duration (Fig. 3B). Addition of 3 $\mathrm{mM} \mathrm{Cs}^{+}$to the solution (Fig. $3 C$ ) completely abolished the remaining instantaneous component of the rectification. The same linear relation observed in the last plot (filled triangles, Fig. 3D) can be seen after the addition of $\mathrm{Cs}^{+}$alone. Thus, we conclude that while $\mathrm{Cs}^{+}$blocks both components of $\mathrm{AR}$, suggesting that $\mathrm{K}^{+}$ions are involved, harmaline blocks $\mathrm{g}_{\mathrm{K}(\mathrm{ol})}$ exclusively.

$\mathrm{Ca}^{2+}$ dependence. Extracellular $\mathrm{Ca}^{2+}$ is required for activation of the time-dependent AR. This may be demonstrated by substituting different divalent cations for $\mathrm{Ca}^{2+}$. The control results obtained at a different membrane level are plotted in Figure $4 \mathrm{~A}$. The plots in Figure $4 B$ were obtained after replacing $\mathrm{Ca}^{2+}$ with $\mathrm{Mn}^{2+}(10 \mathrm{mM})$. Two effects are immediately apparent: The input resistance of the cell increased, and the time-dependent AR was markedly reduced. This can be seen by examining the steadystate current-voltage relation (Fig. 4B). Unlike the control curve (closed circles), the steady state current-voltage relation after $\mathrm{Mn}^{2+}$ appears to be linear; that is, it resembles the high-resistance state of the control results. The reduced $\mathrm{g}_{\mathrm{K}(\mathrm{ol})}$ in $\mathrm{Mn}^{2+}$ Ringer's solution is also reflected as a reduction in the difference between the peak and plateau voltages (open and closed circles, respectively). Note also that $\mathrm{Mn}^{2+}$ blocks the rebound depolarization (Llinás and Yarom, 1981a). A similar set of results, blocking the $\mathrm{g}_{\mathrm{K}(\mathrm{ol})}$ but not the instantaneous conductance, was obtained when $\mathrm{CdCl}_{2}$ was added to the bath. While $\mathrm{Cd}^{2+}$ concentrations as high as $1 \mathrm{~mm}$ were used, concentrations as low as $100 \mu \mathrm{M}$ blocked this AR.

Replacement of $\mathrm{Ca}^{2+}$ by $\mathrm{Ba}^{2+}$. As in the case of the starfish egg (Hagiwara et al., 1978), replacement of $\mathrm{Ca}^{2+}$ by $\mathrm{Ba}^{2+}$ in the extracellular medium produced a reduction of the instantaneous AR in I.O. neurons. Control records at 2 membrane potential levels are shown in Figure $5, A, B$. In Figure $5, C, D$, extracellular $\mathrm{Ca}^{2+}$ is replaced by $2.4 \mathrm{~mm} \mathrm{Ba}^{2+}$. Two effects are observed. First, the membranc resistance increases by a factor of 10 and the neuron is depolarized to $-50 \mathrm{mV}$ (from $-64 \mathrm{mV}$ ). The increased membrane resistance is apparent from the increased charging time and the amplitude of the voltage step generated by a rather small hyperpolarizing current (Fig. $5 C$, triangles in Fig. $5 E$ ). When the membrane is hyperpolarized by about 12 $\mathrm{mV}$ (from $-65 \mathrm{mV}$ ), a marked time-dependent AR appears (Fig. $5 D$ ) and the duration and amplitude of the rebound action potential is increased (Llinás and Yarom, 1981a). The presence of a large, time-dependent, anomalous rectification in Figure
Figure 5. Substitution of $\mathrm{Ba}^{2+}$ for extracellular $\mathrm{Ca}^{2+} . A$, Control response to hyperpolarizing current pulses (circles in $E$ ). $B$ is similar to $(A)$, taken from membrane potential $-10 \mathrm{mV}$ from rest. $C$, Similar records to those in $A$ following replacement of $\mathrm{Ca}^{2+}$ by $\mathrm{Ba}^{2+}$, showing $+14 \mathrm{mV}$ change in membrane potential and increased membrane resistance (open triangles in $E$ ). $D$, Hyperpolarization of the membrane potential to match that in $B$ produces a marked AR, followed by a prolonged rebound low-threshold spike (squares in $E$ ). $E$, Plot of the I-V curve for different amplitude current steps before and after $\mathrm{Ca}^{2+}$ substitution. Plateau, filled symbols; peak, open symbols.
A
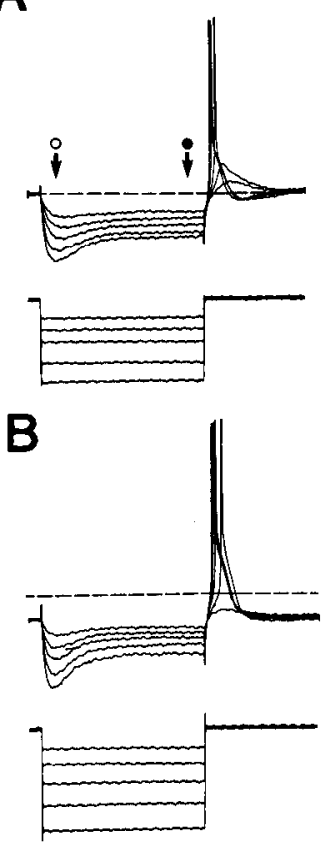

C
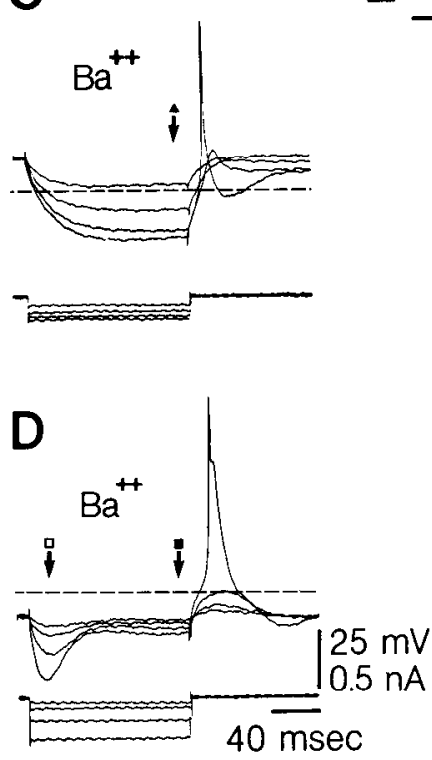

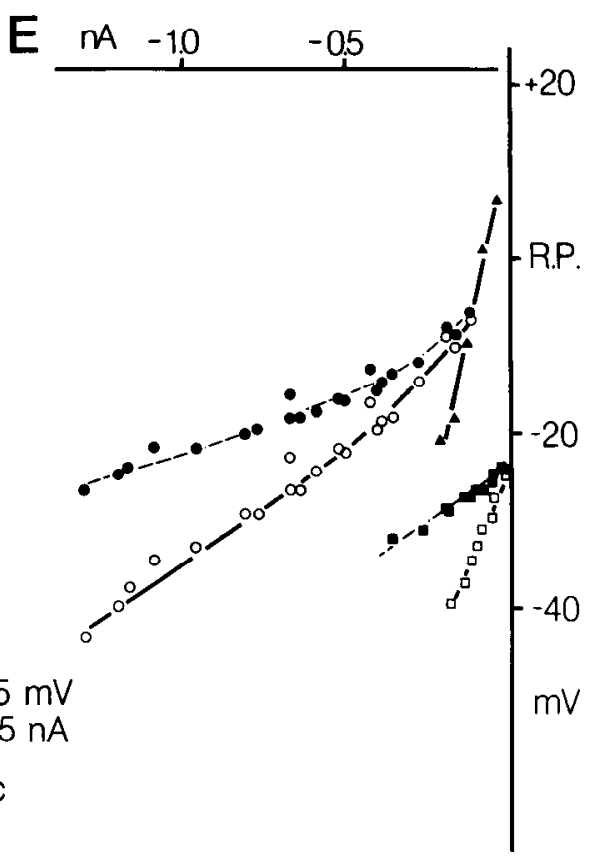




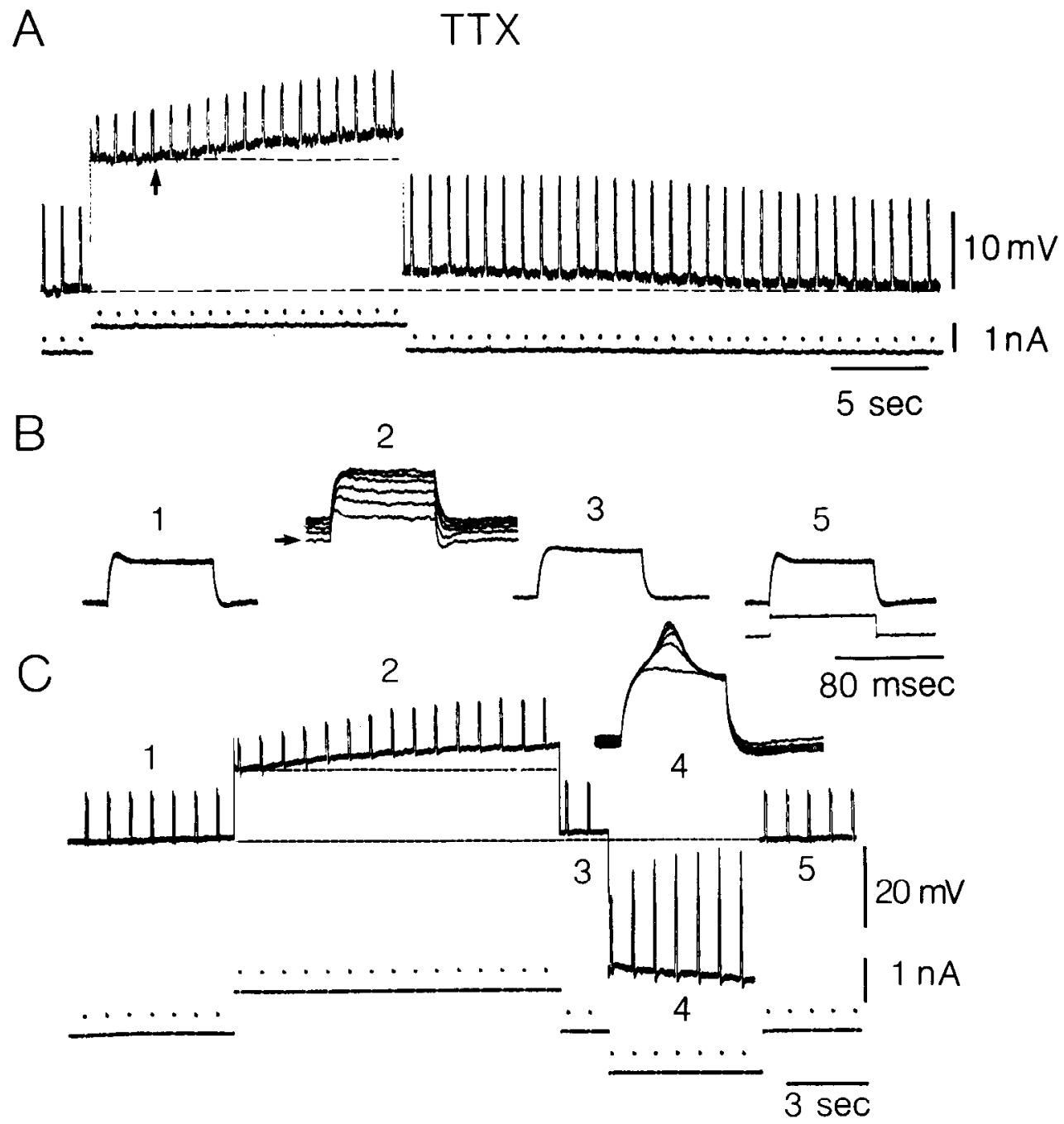

Figure 6. Delayed rectification and its inactivation by prolonged depolarization. $A$, Test current pulses are continually applied as the membrane is depolarized from rest for $16 \mathrm{scc}$. DR is indicated by decrease in the amplitude of the response to test pulses at the start of the depolarization. Inactivation of DR is demonstrated by increase in amplitude of response to test pulses and decrease in membrane potential as depolarization continues. This is shown in detail in $B$ and $C$. $B$, Records marked $1-5$ are responses to test pulses in $C$ at a faster sweep speed. $l(B, C)$, Control responses in TTX. 2, Membrane was abruptly depolarized for $12.5 \mathrm{sec}$. Note that the amplitude of the response to the tcst pulsc is initially reduced (indicating DR). Note also that the test responses approach an asymptote after $9 \mathrm{sec}$ and that the level of membrane potential slowly increases during the depolarizing current pulse, both indicating inactivation of the DR. $3, \mathrm{DC}$ current pulse is terminated but the membrane is more positive than its initial value, while the responses to the test current steps demonstrate no delayed rectification (compare $B_{1}$ and $B_{5}$ ). 4 , Membrane is hyperpolarized by $30 \mathrm{mV}$ and the low-threshold $\mathrm{Ca}^{2+}$ spike is obscrved. Notc that the baseline continues to fall for the duration of the hyperpolarizing pulse, indicating a slow deinactivation of the DR. 5, At the termination of the hyperpolarization, the membrane returns to rest and DR is again seen.

$5 D$ must be considered as evidence that $\mathrm{Ba}^{2+}$ does not significantly block the $\mathrm{g}_{\mathrm{K}(0))}$.

\section{Summary of AR properties}

In brief, the above data indicate that AR in I.O. neurons is comprised of 2 conductances: an instantaneous component that does not require extracellular $\mathrm{Ca}^{2+}$, is resistant to $\mathrm{Ca}^{2+}$ channel blockers $\left(\mathrm{Mn}^{2+}\right.$ and $\left.\mathrm{Cd}^{2+}\right)$, but is blocked by $\mathrm{Cs}^{+}$and $\mathrm{Ba}^{2+}$; and a time-dependent rectifier $\left(\mathrm{g}_{\mathrm{K}(\mathrm{ol})}\right)$ that requires extracellular $\mathrm{Ca}^{2+}$ and is blocked by harmaline, $\mathrm{Cs}^{+}$, and slow $\mathrm{Ca}^{2+}$ channel blockers, but is not affected by $\mathrm{Ba}^{2+}$. This anomalous conductance, we believe, is unique to the inferior olive.

\section{Delayed rectification}

\section{General description}

The presence of delay rectifying conductance that increases during depolarization has been demonstrated in Figure 1. This conductance was further studied by measuring the membrane response to a constant current pulse at different holding potentials. An example of this rectification and its voltage-dependent inactivation, aftcr the application of TTX to the bath to prevent $\mathrm{Na}^{+}$-dependent spike initiation, is shown in Figure $6 A$ (Llinás and Yarom, 1981b). Here constant-amplitude current pulses were used to test the input resistance of the cell before, during, and after a prolonged depolarization produced by $\mathrm{DC}$ injection.
At the outset, the input resistance of the cell was $22.1 \mathrm{M} \Omega$, in keeping with the typical value for I.O. neurons (Llinás and Yarom, 1981a, Table 1). Following the onset of a $1 \mathrm{nA}$ DC injection, the membrane potential fell from -60 to $-43 \mathrm{mV}$ and one obscrved a very rapid increase in membrane conductance, which lowered the input resistance to $17 \mathrm{M} \Omega$, as determined by the DC and to $12 \mathrm{M} \Omega$, as determined by the amplitude of the voltage steps produced by the test current pulses added to the DC injection. The difference between these 2 values was due to the fact that delayed rectification increases with increased depolarization (see Fig. $6 A$ ). After a delay of several seconds (Fig. $6 A$, arrow), the membrane potential step demonstrated a slow positive deviation, reaching a maximum of $4 \mathrm{mV}$ from its initial level (Fig. $6 A$, broken line). The average half-time-to-peak was $7.2 \pm 1.8 \sec (n=12)$. Concomitant with this voltage deviation, there was a progressive increase in the input resistance (as indicated by the amplitude of the test voltage steps), reaching a maximum of $18 \mathrm{M} \Omega$, which persisted for the duration of the DCinjection. Following termination of the DC injection, neither the membrane potential nor the test voltage steps returned to their previous baseline values, but remained above their control levels for more than $20 \mathrm{sec}$. This new state could last for several minutes or even longer, depending on the duration of the conditioning DC injection. Indeed, in a subsequent DC injection to the same cell shown in Figure 6A, inactivation persisted for 
Figure 7. Inactivation of delayed rectification as measured with hyperpolarizing pulses. This set of records is similar to that illustrated in Figure 6, but hyperpolarizing test current steps $(C)$ are used to measure membrane resistance. $l(A, B)$, Control hyperpolarizing potentials in TTX. $2,1.9 \mathrm{nA}, 17.5$ msec current pulse depolarizes the membrane $15 \mathrm{mV}$ and markedly decreases the input resistance (compare $A_{1}$ and $A_{2}$ ). After about $15 \mathrm{sec}$, inactivation of the DR reaches a steady state and removal of the direct current at 3 shows a return of the test voltage response to its normal value, but with a maintained deviation from rest potential, as shown in Figure 6. 4, During a prolonged hyperpolarizing current the membrane continues to hyperpolarize. Note that the AR is clearly present at all values of this hyperpolarized membrane potential.

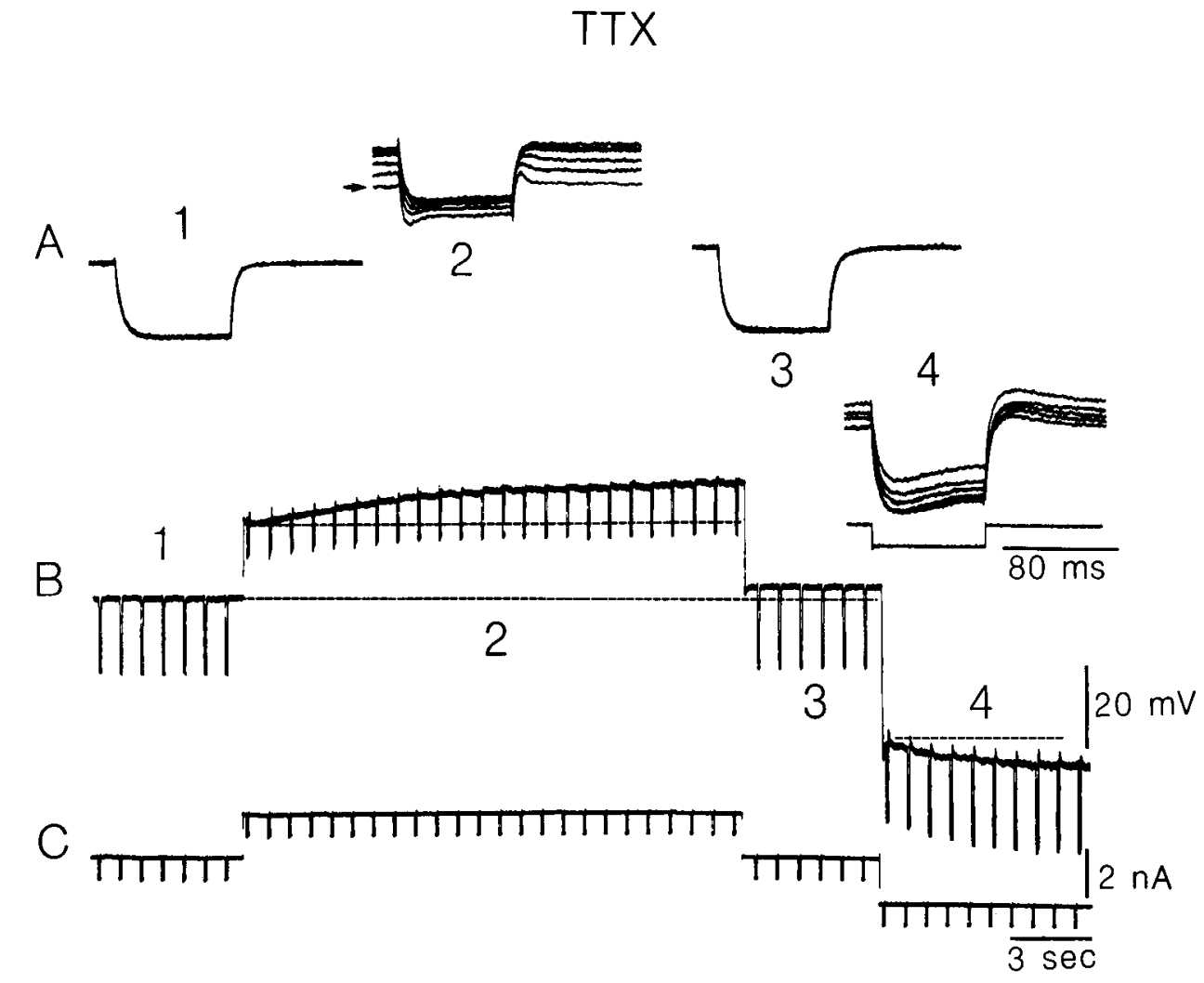

At this stage, an inward current pulse generated a membrane hyperpolarization (Fig. $6 C_{4}$ ) which increased in amplitude with time, indicating an increased input resistance (see below) and produced somatic $\mathrm{Ca}^{2+}$ spiking on the test depolarizing pulses. Note, however, that such activation was also significantly timedependent. After removing the hyperpolarizing current, the membrane resistance and the resting potential level returned to near control values (compare Fig. 6, $B_{1}$ and $B_{5}$ ), indicating that inactivation of the DR was removed by the prolonged hyperpolarization.

An expcriment similar to that illustrated in Figure 6, but using hyperpolarizing test current pulses, is shown in Figure 7. DR was observed at the onset of the prolonged depolarization (Fig. $\left.7 B_{2}\right)$. As the membrane depolarization was continued, both the membrane potential and the amplitude of the hyperpolarizing test response gradually increased (Fig. 7, $A_{2}, B_{2}$ ), indicating inactivation of the DR, as shown in Figure 6 . Note that in this case, in addition to the DR, there was a time-dependent reduction of the amplitude of the hyperpolarizing test response (Fig. $7 A_{2}$, arrow), probably due to an abrupt and delayed reduction of the DR by the brief hyperpolarization (cf. Mauro et al., 1970). Note, also, that the resting potential of this neuron $(-55 \mathrm{mV})$ was such that, in Figure $7 B_{1}$, hyperpolarizing pulses from rest did not activate AR.

Termination of the long current injection after $15 \mathrm{sec}$ (Fig. 7, $A_{3}, B_{3}$ ) demonstrated that the inactivation of the $\mathrm{DR}$ proceeded for many seconds after the cessation of current injection. This is illustrated in Figure $7 A_{3}$ by the increased amplitude of the hyperpolarizing test voltage ( $15 \%$ increase) and by the maintained depolarized membrane level $(3 \mathrm{mV})$ at its initial value (Fig. $7 B_{3}$, middle dashed line). The response to a subsequent long hyperpolarizing pulse (Fig. 7, $A_{4}, B_{4}$ ) confirmed, as is illustrated in Figure 6, that the membrane hyperpolarization was therefore, that at resting potential level $\mathrm{g}_{\mathrm{K}(\text { (inac) }}$ was partly active. 


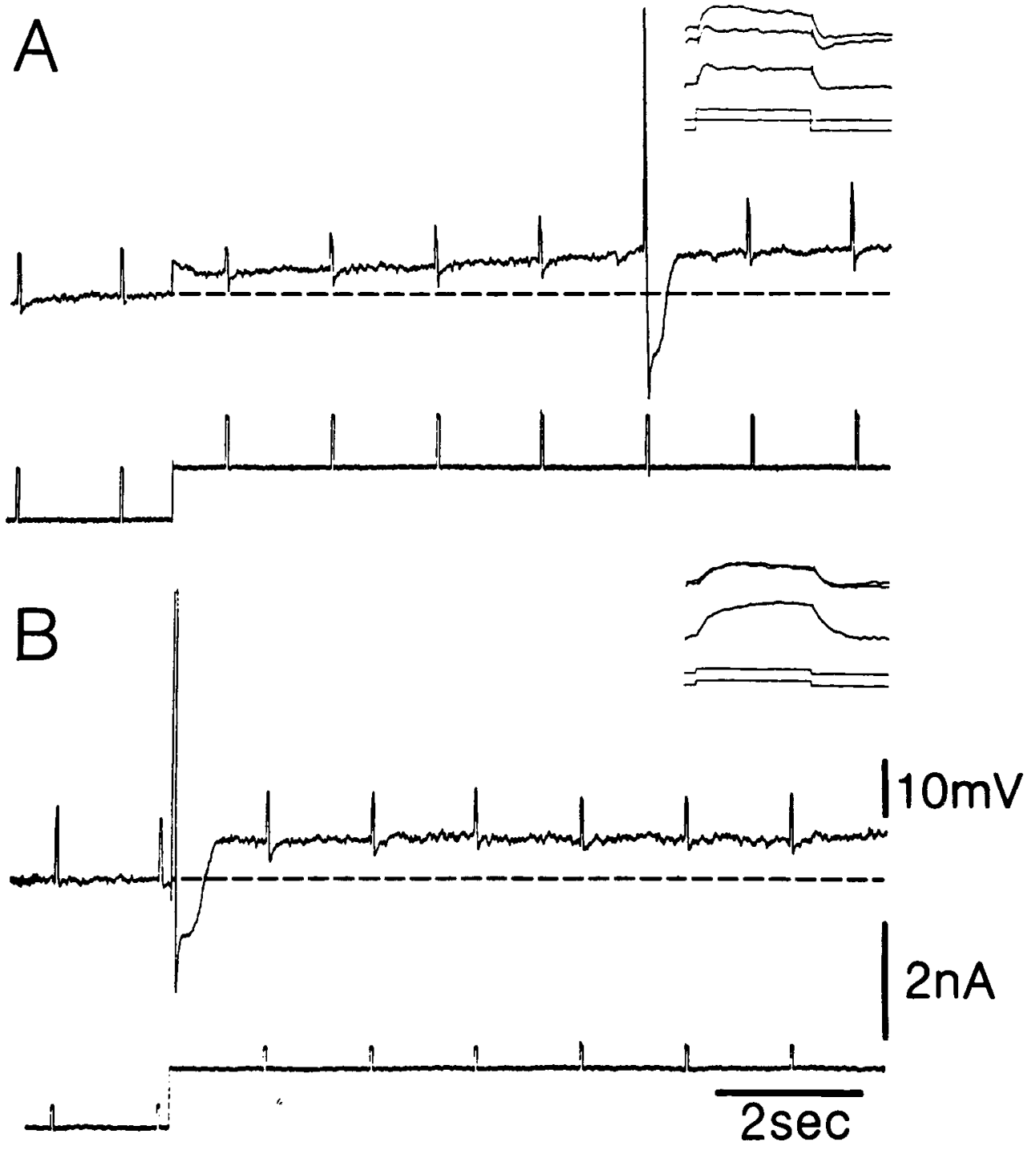

Figure 8. 4-Aminopyridine blocks $\mathrm{g}_{\text {K(nact) }} \cdot A$, Response of an I.O. neuron to depolarizing current pulses during prolonged depolarization. Inset, Depolarizing pulse before (lower trace), at onset (middle trace), and at the cnd (top trace) of the prolonged depolarization. Note the shift in membrane potential and the increase in input resistance during the depolarization. $B$, As in $A$, in the presence of $0.1 \mathrm{~mm} 4$-AP. Note that the depolarizing current pulses are smaller than in $A$ and that at resting level the input resistance is higher. accompanied by $\mathrm{AR}$, which demonstrated a slow inactivation, as indicated by the slow drift of the voltage with time and by the increase in amplitude of the test pulses during the hyperpolarization (Figs. 6, 7). Since the time-dependent component of the AR seems to be unmodified, it is reasonable to assume that the instantaneous component is slowly inactivated. As opposed to the inactivation of $\mathrm{g}_{\mathrm{K} \text { (inact) }}$, the inactivation of the instantaneous AR does not bias the membrane potential at rest. This slow inactivation was blocked by the addition of $\mathrm{Cs}^{+}$to the bathing solution, indicating that it involved a rather slow reduction of an inward $\mathrm{K}^{+}$current.

\section{Effect of 4-aminopyridine on $g_{\text {K(inact })}$}

The above results suggest that the delay rectifier in I.O. neurons is composed of 2 conductances, of which only 1 undergoes slow inactivation. This suggestion is supported by the finding that 4-AP $(0.1 \mathrm{mM})$ produced a blockage of the inactivation process, while a clear rectification was still observed. The actual effect of 4-AP on the delayed rectifier is illustrated in Figure 8. In Figure $8 A$, the familiar effect of a prolonged current injection on input resistance and on membrane potential is shown prior to the addition of 4-AP. As in previous illustrations (Figs. 6, 7), depolarization produces initial activation, followed by a late inactivation of the DR and an increased excitability of the cell (see below). The inset on the upper right of Figure 8 shows, at faster sweep speed, the membrane potential produced by the test current pulses before and at different times after the onset of the prolonged voltage step. Following the administration of 4-AP (Fig. $8 B$ ), a prolonged current step similar to that shown in Figure $8 \mathrm{~A}$ demonstrates a smaller initial increase in conductance and no inactivation. Because the addition of 4-AP blocked this inactivating conductance, the test pulses used in this sequence were smaller in amplitude than those shown in Figure $8 A$ (see inset); otherwise, the cell would have generated an action with each current pulse. The inset to the right in Figure $8 B$ shows the pulses prior to and after the depolarization step, which illustrate that after the initial change in membrane resistance following the DC injection, the amplitude of the test potential remained constant during the prolonged voltage step. These results show that the $\mathrm{DR}$ in 1.0 . neurons is indeed composed of 2 conductances, both increased during depolarization. Howcver, only 1 of them, $g_{K(\text { inact) }}$, was blocked by low concentrations of 4-AP and demonstrated a slow inactivation.

Effect of $\mathrm{Ca}^{2+}$ and $\mathrm{Ba}^{2+}$ on $\mathrm{g}_{\text {K(inact })}$

$\mathrm{Ca}^{2+}$. A distinct modification of the DR was observed in I.O. neurons when $\mathrm{Ca}^{2+}$ was removed from the bath. Indeed, DR inactivation required the presence of extracellular $\mathrm{Ca}^{2+}$. One test 

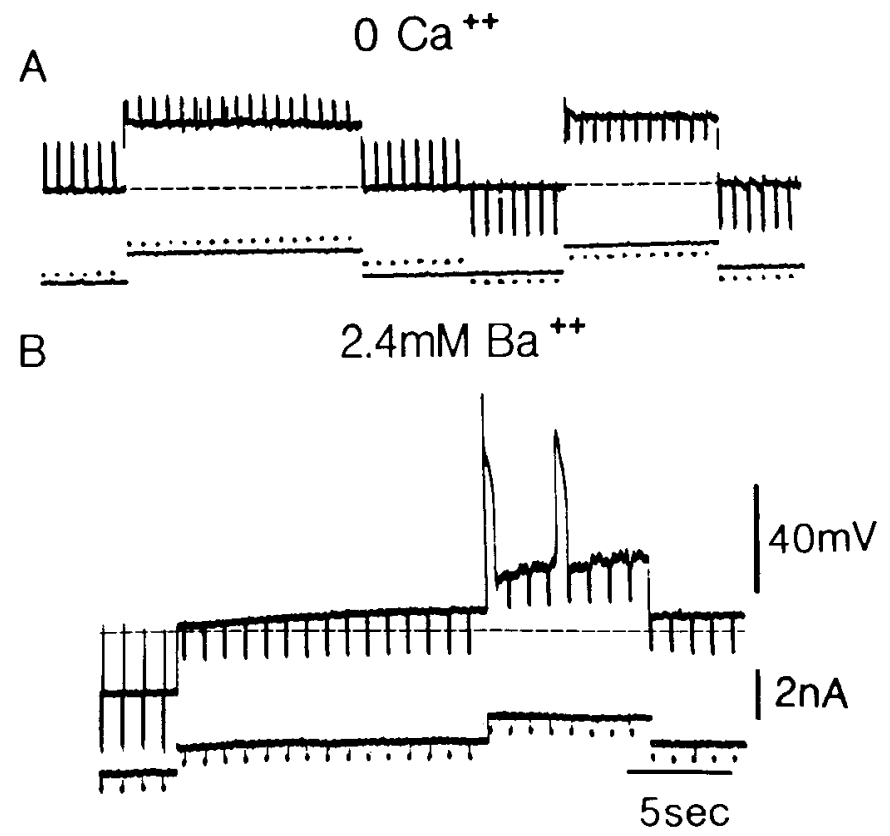

Figure 9. Inactivation of $\mathrm{g}_{\mathrm{K}(\text { inact) }}$ requires the presence of $\mathrm{Ca}^{2+}$ or $\mathrm{Ba}^{2+}$ ions. $A$, Response of an I.O. neuron to hyperpolarizing and depolarizing current pulses during prolonged depolarization in the presence of TTX $\left(10^{-5} \mathrm{M}\right)$ and low concentration of extracellular $\mathrm{Ca}^{2+}$ ions. Note that the prolonged depolarization induces a large increase in conductance, which does not inactivate. $B$, In the same cell, $2.4 \mathrm{~mm}$ of $\mathrm{Ba}^{2+}$ ions, demonstrating the process of inactivation after the results in $A$ had been obtained.

of this phenomenon is illustrated in Figure $9 A$, which shows experiments similar to those in Figures 6 and 7. Here, polarizations of more than $20 \mathrm{sec}$ in a medium containing less than $0.1 \mathrm{~mm}$ extracellular $\mathrm{Ca}^{2+}$ produced no observable inactivation of the DR. In addition, because of the low $\mathrm{Ca}^{2+}{ }_{0}$, both the low- and high-threshold spikes were abolished. Results similar to those seen in Figure 9 were obtained when $\mathrm{Cd}^{2+}$ or $\mathrm{Co}^{2+}$ were added to the bathing solution.

$\mathrm{Ba}^{2+}$. A rather different outcome was observed when $\mathrm{Ba}^{2+}$ (at $2.4 \mathrm{~mm}$ final concentration) was added to the bathing solution (Fig. 9B). Two distinct actions of $\mathrm{Ba}^{2+}$ on the resting I.O. neuronal membrane were encountered: It depolarized the cell by up to $15 \mathrm{mV}$, and it produced a large increase in membrane resistance. If the membrane potential was further depolarized by a direct current (Fig. 9B), DR was observed, as well as its inactivation with time. Note, also, that the rather prolonged $\mathrm{Ba}^{2+}$ action potentials elicited by further depolarization are not followed by the usual fast and rather sizable AHP seen with the normal $\mathrm{Ca}^{2+}$-dependent spikes in these cells (Llinás and Yarom, 1981a). This finding is in agreement with the fact that $g_{\mathrm{K}_{(}(\mathrm{a})}$ is not activated by $\mathrm{Ba}^{2+}$ (Eckert and Lux, 1976).

\section{$g_{\text {K(inac) }}$ and neuronal excitability}

Direct stimulation. Inactivation of $\mathrm{g}_{\mathrm{K}(\text { (inat) }}$ not only increased the input resistance, but also the excitability of I.O. neurons. As illustrated in Figure 10, outward subthreshold current pulses were delivered at rest after TTX application to the bath. In Figure $10 B$, after a DC stcp similar to that shown in Figure $6 A$, $C$, the test voltage pulses were initially small. As the DR inactivated with time (Fig. 10B), the membrane potential reached firing level for the high-threshold (dendritic) spike (Llinas and Yarom, 1981a). This firing level was lower than that observed prior to inactivation of the $\mathrm{DR}$, indicating that, in addition to a lower threshold due to the reduction in $\mathrm{K}^{+}$conductance, the increased input resistance that accompanies DR inactivation also increased the length constant of the neuron and, thus, dendritic firing could occur more readily.

Synaptic input. A second test for the increased excitability of I.O. neurons following inactivation of the DR is illustrated in Figure $10 \mathrm{C}$. Synaptic potentials were recorded intracellularly following peri-olivary stimulation of the brain stem slice (Llinás and Yarom, 1981a). This stimulus generated a synaptic potential, as is shown at fast sweep speed in Figure $10 D$ (denoted "1"). This potential had a close-to-constant amplitude and duration for a given stimulus amplitude (5 superimposed sweeps), as is illustrated in Figure $10 \mathrm{Cl}$, where the same potentials are shown at a slower sweep speed. Following a DC injection in Figure $10 C 2$, the typical DR and its inactivation were observed much as illustrated in Figures 6-8. Excitatory synaptic potentials generated during the inactivation period could generate full action potentials, although the amplitude of the individual synaptic potentials was smaller than that prior to depolarization (note that in Fig. 10D2 the first 5 stimuli are superimposed). At the end of the DC injection, the membrane potential remained slightly depolarized from its previous resting value and the amplitude of the synaptic potentials was increased from control in Figure $10 C 3$, which can also be seen at a faster sweep speed (Fig. 10D3, 5 records superimposed).

\section{Discussion}

This paper describes the characteristics of DR and AR in I.O. neurons. These 2 types of rectification confer 2 rather important integrative properties on I.O. cells. Both AR and DR and their time-dependent inactivation provide a means for long-term modifiability of the integrative properties of I.O. neurons. Table 1 summarizes the different ionic conductances encountered in I.O. neurons, their voltage dependence, and their blockage by various ions and drugs. While the in vitro preparation does not permit further experimental elaboration of the question within the context of the organization of movement control, the longterm modifiability of the I.O. neuron must ultimately have a significant role in the organization of the olivo-cerebellar system.

With regard to the precise mechanisms that ultimately generate the complex set of conductances described in this paper, it must be remembered that, even under slice conditions, both electrotonic and chemical synaptic interactions do occur in our preparation (Llinás and Yarom, 1981a) and, thus, some of our findings may be complicated by such interactions. Nevertheless, because the results presented here were invariably repeatable from one preparation to the next, and the results were virtually identical under conditions in which nerve cells were recorded from large clusters or in very small islands (due to the cutting plane of the sections), we consider that the electrophysiology presented here reflects overwhelmingly the membrane properties of single neurons.

\section{Dynamic aspects of long-term I.O. excitability and integration}

\section{Delayed rectification}

The results of the experiments described here indicate that the membrane properties of I.O. neurons are modified when the cell is slightly depolarized from its normal resting value $(-65$ $\mathrm{mV}$ ). Thus, as illustrated in Figure 1, the application of a ramp 


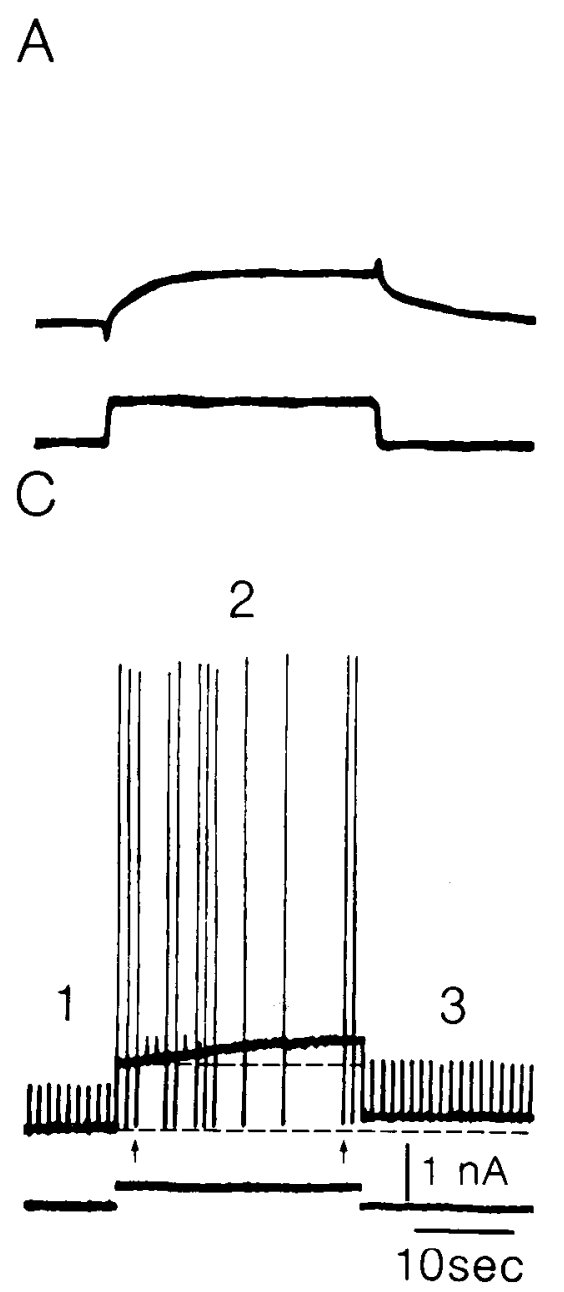

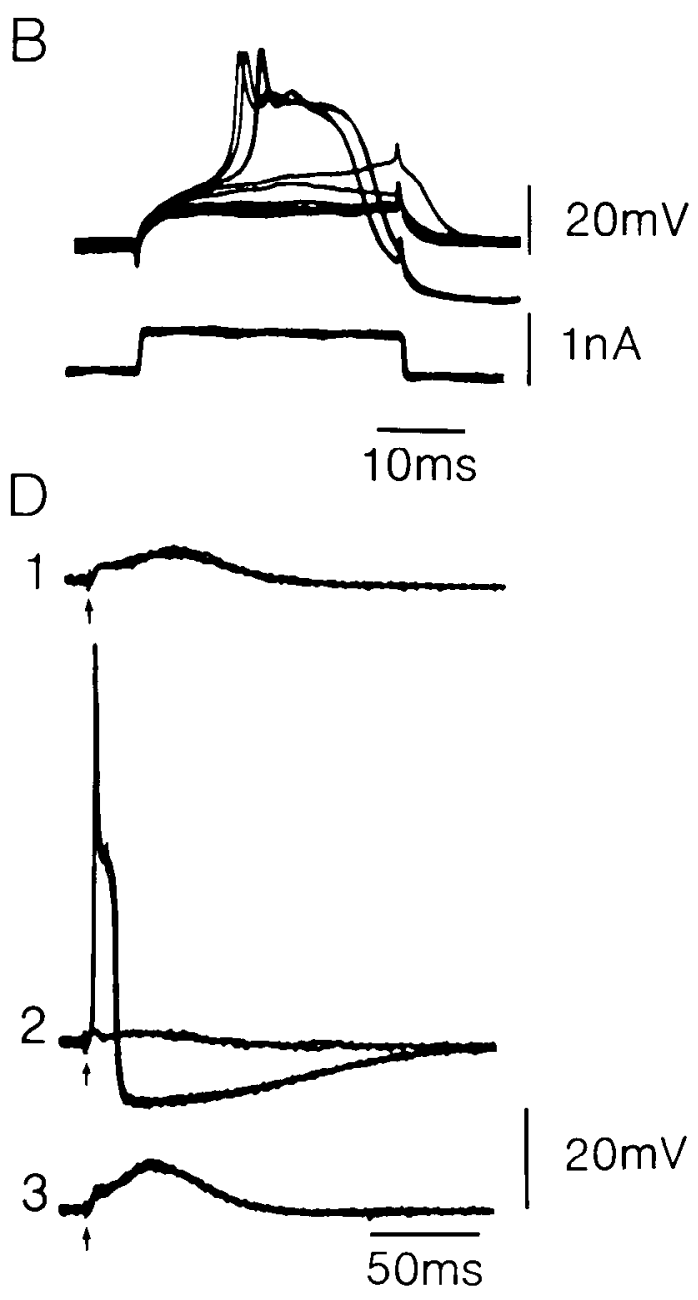

Figure 10. Inactivation of $\mathrm{g}_{\mathrm{K}(\text { inac) }}$ increases the excitability of I.O. neurons. Subthreshold current pulses at resting level $(A)$ and during DC depolarization $(B)$ demonstrate that the inactivation of $g_{\kappa(\text { inac) }}$ enables the activation of full dendritic responses. $C, D$, Inactivation of $g_{\text {K(inact) }}$ induces an increase in synaptic potential. The synaptic potentials were recorded before (1), during (2), and after (3) prolonged depolarizing current pulse. Note that in 3 , although the membrane potential is lower, the EPSP is larger. $A$ and $B$ were oblained in the presence of TTX. depolarization produces a deviation from linearity that can in fact be very large and that is accompanied by a reduction in input resistance large enough, on occasion, to reduce the resting input resistance to one-third. This rather transient reduction makes the firing of the neuron with transient depolarizing pulses rather difficult. Indeed, currents of about $1 \mathrm{nA}$ are generally required to activate the cell from its rest value.

This DR is generated by the activation of 2 different voltagedependent $\mathrm{K}^{+}$conductances (see Table 1), which we refer to as $\mathrm{g}_{\mathrm{K}}$ and $\mathrm{g}_{\mathrm{K} \text { (inact) }}$, respectively. The $\mathrm{g}_{\mathrm{K} \text { (inact) }}$ demonstrates long-term inactivation. Indeed, an I.O. cell must be depolarized for several tens of seconds for the inactivation to be complete. At this time the linear voltage range of the membrane resistance is extended to near the firing level of the neuron, and the current necessary to activate a full somadendritic action potential is about onefifth that required during the peak of the DR. The actual mechanism for the depolarization and the increased input resistance may be considered either a voltage inactivation of an outward $\mathrm{K}^{+}$current or an extracellular $\mathrm{K}^{+}$accumulation (Frankenhäuser and Hodgkin, 1956). The latter can be ruled out on the basis of 2 different findings: (1) The membrane resistance increase during this depolarization is the same for depolarizing and hyperpolarizing current pulses. Indeed, the results in records 1-3 of Figures 6 and 7 indicate that the increase in the amplitude of the depolarizing pulse is not due to an extracellular $\mathrm{K}^{+}$accumulation that, by reducing the driving force for $\mathrm{K}^{+}$, could produce an increased voltage step. If this were the case, an asymmetry in membrane resistance should be observed using depolarizing and hyperpolarizing test current pulses. This asymmetry was not found. (2) More important, a variation of $\mathrm{K}^{+}{ }_{0}$ sufficient to depolarize the membrane by up to $5 \mathrm{mV}$ would have a marked effect on the amplitude of the AHP following spike activation (Frankenhäuser and Hodgkin, 1956). Indeed, during the large increase in the $\mathrm{K}^{+}$conductance that generates the AHP, the membrane behaves more like a $\mathrm{K}^{+}$electrode than during rest. However, in all cases where action potentials were evoked during the depolarization phase, the amplitude of the AHP was similar to those of control action potentials (Fig. 10). The possibility that $\mathrm{g}_{\mathrm{K} \text { (inact) }}$ is associated with slow inward current seems an unlikely explanation, as a substantial inward current should have been accompanied by a decreased resistance. The observed increase in input resistance caused either by negative or positive test pulses clcarly indicates that the major phenomenon underlying the slow depolarization is a reduction of a conductance to an ion that has a negative equilibrium potential. However, we cannot exclude the possibility that, owing to the high input resistance, a more efficient spread of current into remote regions of the dendrites activates an inward current whose underlying conductance change is electrotonically too distant to be detected. Even under such circumstances, the main trigger of the observed phenomenon is an inactivation of the DR. Finally, since $\mathrm{g}_{\mathrm{K} \text { (nac) }}$ is $\mathrm{Ca}^{2+}$-dependent and is blocked by 4-AP, our results suggest a similarity of $\mathrm{g}_{\mathrm{K} \text { (inact) }}$ with the $\mathrm{A}$ current in Hermissenda (Alkon, 1984). Indeed, the above evidence strong- 


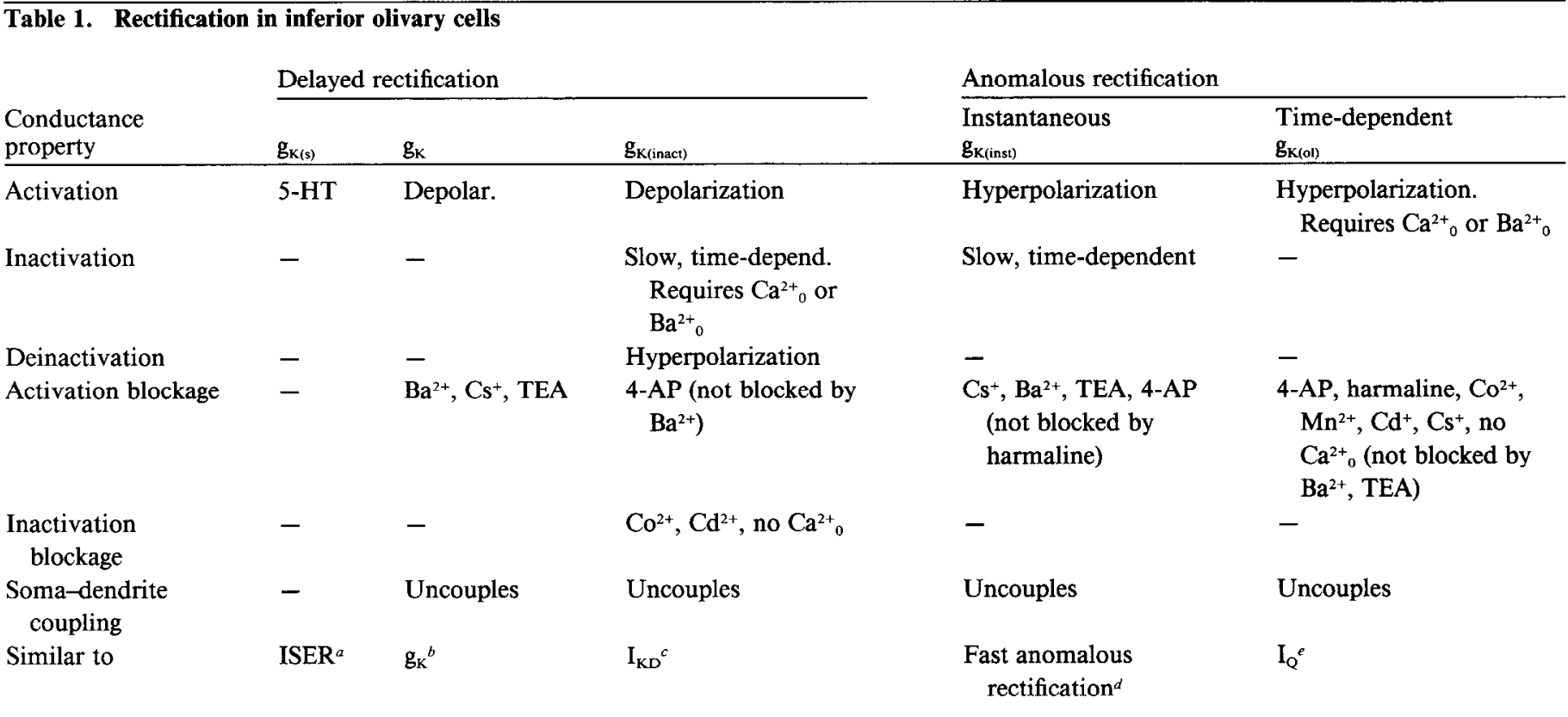

\footnotetext{
${ }^{a}$ Klein and Kandel (1980).

${ }^{b}$ Hodgkin and Huxley (1952).

' Akaike et al. (1983).

${ }^{d}$ Scholfield (1978); Constanti and Galvan (1983); Hagiwara et al. (1976); Ohmori (1978); Katz (1949); Adrian (1969).

' Halliwell and Adams (1982).
}

ly supports the conclusion that the inactivation of an A-type current is the likely mechanism for this long-term modulation of membrane properties.

The prolonged time course of inactivation of the DR makes it a key participant in the long-term modulation of the excitability of I.O. neurons. Moreover, because delayed inactivation seems to be dependent on extracellular $\mathrm{Ca}^{2+}$ (Table 1), one must consider the possibility that $\mathrm{Ca}^{2+}$ entry may play a direct role, or act as a second messenger, triggering the inactivation of this $\mathrm{K}^{+}$conductance. In agreement with this view is the observation that ions that block the slow $\mathrm{Ca}^{2+}$ current, such as $\mathrm{Mn}^{2+}$ or $\mathrm{Cd}^{2+}$, prevent this inactivation. It is clear that, in addition to the membrane resistance increase seen with the inactivation of the $\mathrm{DR}$, there is a concomitant increased excitability for $\mathrm{Ca}^{2+}$ spiking (Fig. 10). This is consistent with the view that inactivation of the DR brings the dendrites electrotonically closer to the soma and thus to the site of $\mathrm{Na}^{+}$spike initiation.

\section{Anomalous rectification}

The central findings of this paper regarding AR in I.O. neurons can be summarized as follows (see also Table 1): After harmaline administration at doses larger than required for complete blockage of the time-dependent AR, a component of AR is still present; it is not time-dependent and can be blocked by addition of $\mathrm{Ba}^{2+}$ or $\mathrm{Cs}^{+}$, or by removal of $\mathrm{Ca}^{2+}$ from the extracellular medium. These findings force us to conclude that there are at least 2 distinct AR conductances.

AR in I.O. neurons is characterized, as in other cclls (Katz, 1949; Hagiwara et al., 1976; Ohmori, 1978; Scholfield, 1978; Brown and DiFrancesco, 1980; DiFrancesco and Ojeda, 1980; Yanigahara and Irisawa, 1980; Halliwell and Adams, 1982; Constanti and Galvan, 1983), by an increased conductance when the cell is hyperpolarized from the resting membrane potential. This conductance increase, as in other neurons, is most likely due to an increased permeability to $\mathrm{K}^{+}$ions, especially since it is blocked by $\mathrm{Cs}^{+}$, an ion known to block conductances in other cells (Adelman and French, 1978). Indeed, the increased conductance underlying the AR of I.O. cells resembles in many respects the $I_{Q}$ current observed in hippocampal pyramidal cells (Halliwell and Adams, 1982). However, in the I.O., AR seems to be composed of 2 distinct components, the instantaneous AR and the $\mathrm{g}_{\mathrm{K}(\mathrm{ol})}$. The similarities between the $\mathrm{g}_{\mathrm{K}(\mathrm{ol})}$ and the instantaneous AR are (1) their activation by membrane hyperpolarization and (2) their blockage by $\mathrm{Cs}^{+}$. The $\mathrm{g}_{\mathrm{K}(\mathrm{ol})}$ component differs from the instantaneous $A R$ in that it is not blocked by external $\mathrm{Ba}^{2+}$ (in doses sufficient to block the $\mathrm{Ca}^{2+}$-dependent $\mathrm{K}^{+}$conductance) and does not inactivate. Moreover, the $\mathrm{g}_{\mathrm{K}(\mathrm{ol})}$ requires the presence of either $\mathrm{Ba}^{2+}$ or $\mathrm{Ca}^{2+}$ in the extracellular medium for its activation and is blocked by $\mathrm{Mn}^{2+}$ or $\mathrm{Cd}^{2+}$. In this respect, the $\mathrm{g}_{\mathrm{K}(\mathrm{ol})}$ differs from $\mathrm{I}_{\mathrm{Q}}$, which is apparently independent of $\mathrm{Ca}^{2+}$ and is $\mathrm{Na}^{+}$- as well as $\mathrm{K}^{+}$-dependent (Halliwell and Adams, 1982). Finally, $\mathrm{g}_{\mathrm{K}(\mathrm{ol})}$ is blocked by harmaline.

\section{Influence of $D R$ and $A R$ on oscillatory behavior}

Both DR and AR are characterized by voltage-dependent conductance states. Since hyperpolarization deinactivates the somatic $\mathrm{Ca}^{2+}$ action potential, in addition to producing $\mathrm{AR}$, the functional significance of $A R$ is clear. By combining an increased conductance with an increased somatic excitability, hyperpolarization of I.O. cells tends to separate the electrical excitability of the soma from that of the dendrites; that is to say, the lowthreshold spike is generated at a point when AR has decoupled the soma from the dendrite. This uncoupling can be eliminated by the addition of $\mathrm{Cs}^{+}$or harmaline to the bath (Fig. 3). Under these circumstances, one sees that the rebound somatic $\mathrm{Ca}^{2+}$ spike, which normally generates 1 or $2 \mathrm{Na}^{2+}$ action potentials and returns to a hyperpolarizing state, is capable of activating a large dendritic spike even in the presence of TTX - a phe- 
nomenon that has never been observed in the I.O. under normal conditions. In addition, harmaline has a direct effect on the somatic $\mathrm{Ca}^{2+}$ spike, as it increases the membrane excitability. As is discussed in another publication (Llinás and Yarom, 1986), harmaline facilitates oscillatory firing by blocking $\mathrm{g}_{\mathrm{K}(\mathrm{o})}$ and moving the activation of $\mathrm{Ca}^{2+}$ current to the right on the currentvoltage plot.

From the above results, then, we may conclude that the conductances in the I.O. are organized in such a way as to drive the neuron toward oscillatory firing. This oscillatory behavior is produced because somatic $\mathrm{Na}^{+}$action potentials are capable of activating dendritic spikes that, being $\mathrm{Ca}^{2+}$-dependent, activate a $\mathrm{Ca}^{2+}$-dependent $\mathrm{K}^{+}$conductance change. This conductance, as we have demonstrated (Llinás and Yarom, 1981a), generates a long-lasting AHP large enough to deinactivate the somatic "rebound" $\mathrm{Ca}^{2+}$ conductance that generates the lowthreshold spike. This in turn may either activate somatic $\mathrm{Na}^{+}$ spikes and dendritic $\mathrm{Ca}^{2+}$ spikes or, more commonly, activate only an $\mathrm{Na}^{+}$spike. Because of the inward $\mathrm{Ca}^{2+}$ current flowing during the low-threshold spike, a hyperpolarization is produced, which repeats the cycle and allows the cell to generate oscillatory firing. Under conditions in which the cell is depolarized because the membrane resistance is larger, somatic and dendritic spikes can be sequentially generated. Here, however, owing to the larger $\mathrm{Ca}^{2+}$ entry into the cell, the interspike period is increased and thus, as shown in another publication (Llinás and Yarom, 1986), the frequency of the I.O. oscillation can be modulated by the degree of invasion of the $\mathrm{Ca}^{2+}$ action potential into the I.O. dendrites. This itself is modulated by the level of AR and DR.

\section{References}

Adams, P. R., D. A. Brown, and A. Constanti (1982) M-currents and other potassium currents in bullfrog sympathetic neurons. J. Physiol. (Lond.) 330: 537-572.

Adelman, W. J., Jr., and R. J. French (1978) Blocking of the squid axon potassium channel by external caesium ions. J. Physiol. (Lond.) 276: $13-25$.

Adrian, R. H. (1969) Rectification in muscle membrane. Prog. Biophys. Mol. Biol. 19: 339-369.

Akaike, N., A. M. Brown, G. Dahl, H. Higashi, G. Isenberg, Y. Tsuda, and A. Yatani (1983) Voltage-dependent activation of potassium current in helix neurones by endogenous cellular calcium. J. Physiol. (Lond.) 334: 309-324.

Alkon, D. L. (1984) Calcium-mcdiated reduction of ionic currents: A biophysical memory trace. Science 226: 1037-1045.

Brown, D. A., and P. R. Adams (1980) Muscarinic suppression of a novel voltage-sensitive $\mathrm{K}^{+}$current in a vertebrate neurone. Nature 5748: 673-676.

Brown, H., and D. DiFrancesco (1980) Voltage clamp investigation of membrane currents underlying pace-maker activity in rabbit sinoatrial node. J. Physiol. (Lond.) 308: 331-351.

Constanti, A., and M. Galvan (1983) Fast inward-rectifying current accounts for anomalous rectification in olfactory cortex neurones. $J$. Physiol. (Lond.) 335: 153-178. de Montigny, C. and Y. Lamarre (1973) Rhythmic activity induced by harmaline in the olivo-cerebellar-bulbar system of the cat. Brain Res. 53: 81-95.

DiFrancesco, D., and C. Ojeda (1980) Properties of the current in the sinoatrial node of the rabbit compared with those of the current $I_{K 2}$ in Purkinje fibers. J. Physiol. (Lond.) 308: 353-367.

Eckert, R., and H. D. Lux (1976) A voltage-sensitive persistent calcium conductance in neuronal somata of helix. J. Physiol. (Lond.) 254: 129-151.

Frankenhäuser, B., and A. L. Hodgkin (1956) The after-effects of impulses in the giant nerve fibres in Loligo. J. Physiol. (Lond.) 131: 341-376.

Hagiwara, S., S. Miyazaki, and N. P. Rosenthal (1976) Potassium current and the effect of cesium on this current during anomalous rectification of the egg cell membrane of starfish. J. Gen. Physiol. 67. 621-638.

Hagiwara, S., S. Miyazaki, W. Moody, and J. Patlak (1978) Blocking effects of barium and hydrogen ions on potassium current during anomalous rectification in the starfish egg. J. Physiol. (Lond.) 279: 167-185.

Halliwell, J. V., and P. R. Adams (1982) Voltage-clamp analysis of muscarinic excitation in hippocampal neurons. Brain Res. 250: 7192.

Hodgkin, A. L., and A. F. Huxley (1952) A quantitative description of membrane current and its application to conduction and excitation in nerve. J. Physiol. (Lond.) 117: 500-544.

Katz, B. (1949) Les constantes electriques de la membrane du muscle. Arch. Sci. Physiol. 3: 285-300.

Klein, M., and E. R. Kandel (1980) Mechanism of calcium current modulation underlying presynaptic facilitation and behavioral sensitization in Aplysia. Proc. Natl. Acad. Sci. USA 77: 6912-6916.

Llinás, R., and M. Sugimori (1980) Electrophysiological properties of in vitro Purkinje cell somata in mammalian cerebellar slices. J. Physiol. (Lond.) 305: 171-195.

Llinás, R., and R. A. Volkind (1973) The olivo-cerebellar system: Functional properties as revealed by harmaline-induced tremor. Exp. Brain Res. 18: 69-87.

Llinás, R., and Y. Yarom (1981a) Electrophysiological properties of mammalian inferior olivary cells in vitro: Different types of voltagedependent ionic conductances. J. Physiol. (Lond.) 315: 549-567.

Llinás, R., and Y. Yarom (1981b) Properties and distribution of ionic conductances generating electroresponsiveness of mammalian inferior olivary neurones in vitro. J. Physiol. (Lond.) 315: 569-584.

Llinás, R., and Y. Yarom (1986) Oscillatory properties of guinea pig inferior olivary neurons and their pharmacological modulation: An in vitro study. J. Physiol. (Lond.) 376: 163-182.

Mauro, A., F. Conti, F. Dodge, and R. Schor (1970) Subthreshold behavior and phenomenological impedance of the squid giant axon. J. Gen. Physiol. 55: 497-523.

Ohmori, H. (1978) Inactivation kinetics and steady-state current noise in the anomalous rectifier of tunicate cgg cell membranes. J. Physiol. (Lond.) 281: 77-99.

Scholfield, C. N. (1978) Electrical properties of neurones in the olfactory cortex slice in vitro. J. Physiol. (Lond.) 275: 535-546.

Thompson, S. H., and R. W. Aldrich (1980) Membrane potassium channels. In Cell Surface and Neuronal Function, C. W. Cotman, G. Poste, and G. L. Nicolson, eds., pp. 49-85, Elsevier/North Holland, Amsterdam.

Yanigahara, $K$., and H. Irisawa (1980) Inward current activated during hyperpolarization in the rabbit sinoatrial node cell. Pfluegers Arch. 385: 11-19. 